\title{
Gene expression pattern in oral cancer cervical lymph node metastasis
}

\author{
YOSHIKUNI KATO ${ }^{1}$, KATSUHIRO UZAWA ${ }^{1,4}$, KENGO SAITO $^{1}$, DAI NAKASHIMA ${ }^{1}$, MASAKI KATO ${ }^{2}$, \\ YOSHINORI NIMURA ${ }^{2}$, NAOHIKO SEKI ${ }^{2,3}$ and HIDEKI TANZAWA ${ }^{1,3,4}$

\begin{abstract}
Departments of ${ }^{1}$ Clinical Molecular Biology and ${ }^{2}$ Functional Genomics; ${ }^{3}$ Center of Excellence (COE) Program in The 21 st Century, Graduate School of Medicine, Chiba University; ${ }^{4}$ Division of Dentistry and Oral-Maxillofacial Surgery, Chiba University Hospital, 1-8-1 Inohana, Chuo-ku, Chiba 260-8670, Japan
\end{abstract}

Received July 11, 2006; Accepted August 10, 2006

\begin{abstract}
Treatment protocols for malignant tumors in the oral cavity differ greatly based on the presence of cervical lymph node metastasis. We applied gene expression profiling to the pathological lymph node status and used a training-test approach to evaluate the reliability of cDNA microarraybased classifications of 15 matched resected primary oral squamous cell carcinomas (OSCCs) and corresponding normal oral tissues. The clustering of all the microarray data was separated into two groups based on metastatic node positivity and node negativity. Furthermore, a 20-gene signature was identified that differentiated the testing set $(n=8)$ with high classification accuracy (88\%). Our findings support the hypothesis that the lymph node metastasis status can be predicted using the gene expression patterns of the primary OSCC, and may be a powerful tool in identifying patients at high risk of lymph node metastasis.
\end{abstract}

\section{Introduction}

Metastasis, the dissemination of tumor cells that colonize in new areas of the body, progresses via the bloodstream or the lymphatic system. Typically, $50 \%$ of patients with oral squamous cell carcinomas (OSCCs) have detectable lymph node involvement at presentation. Patients with lymph node metastasis have a markedly worse prognosis than patients without metastasis. Only $25 \%$ to $40 \%$ of patients with lymph node metastasis at presentation survive 5 years, compared to $\sim 90 \%$ of patients without metastasis (1).

This concept of tumor heterogeneity might indicate that studying the bulk tumor is not useful for predicting metastasis,

Correspondence to: Dr Katsuhiro Uzawa, Department of Clinical Molecular Biology, Graduate School of Medicine, Chiba University, 1-8-1 Inohana, Chuo-ku, Chiba 260-8670, Japan

E-mail: uzawak@faculty.chiba-u.jp

Key words: oral squamous cell carcinoma, lymph node metastasis, gene expression, microarray, clustering algorithms in Cluster since a large number of poorly metastatic cells might obscure the properties of a small number of highly metastatic cells. However, gene signatures have been identified in several tumor types that correlate primary tumor gene expression with an increased risk of metastatic expression $(2,3)$. These data are part of a growing body of studies indicating that the genetic signature of most cells in a primary tumor is extremely valuable. Identifying the differences in gene expression between metastatic and nonmetastatic primary tumors may expose the patterns of metastatic potential and serve as the basis for clinical testing for metastatic potential at biopsy.

Research in metastasis has focused largely on hematogenous metastasis, although metastasis through the lymphatic system is also common in many cancers. Certain data indicate that hematogenous metastasis and lymphatic metastasis differ markedly (4). Studies of breast, lung, colon, and pancreatic cancers have begun to address lymphatic metastasis, but these diseases are also prone to the confounding factor of distant metastasis $(5,6)$. One study has identified a gene signature for recurrent disease in head and neck squamous cell carcinoma (HNSCC), and several studies have investigated the changes in gene expression from normal tissue to cancer tissue, but studies of lymphatic metastasis have been limited by the small number of genes assessed, the lack of a rigorous efficacy test of the metastatic signature (7-12), or both.

Oral cancer accounts for $2.6 \%$ of all cancers worldwide (13), and OSSC is the most frequently occurring malignancy in the oral cavity. The most important prognostic indicator for patients with OSCC is metastasis to the cervical lymph nodes or distant organs. Esophageal SCC is intractable, because it metastasizes to the lymph node even when the tumor is superficial. Many gene mutations are associated with metastatic potential (14). Custom cDNA arrays have been constructed (15) and used to identify new candidate genes that play an important role in esophageal carcinogenesis (16). Analysis of cDNA microarrays is a convenient method to detect differential expression $(17,18)$, and by using this method, thousands of genes can be analyzed rapidly. By comparing gene expression profiles between tissue from oral cancer node-positive and that from oral cancer node-negative, we identified a gene that might be involved in oral cancer lymph node metastasis. We investigated whether the differences in gene expression between node-positive and node-negative 
primary tumor groups could be used to predict the nodal status of an independent patient set and whether such a discriminatory gene signature is similar to those predicting lymphatic metastasis. The goals of this study were to analyze publicly available gene expression data from OSCC samples and identify gene expression patterns that correlate with lymph node metastases and patterns of gene expression in an independent testing set.

\section{Materials and methods}

Tissue specimens and total RNA isolation. Tissue samples for RNA extraction, with patient-matched normal epithelium where available, were obtained at the time of surgical resection at Chiba University Hospital after the patient's informed consent had been obtained under a protocol reviewed and approved by the institutional review board of Chiba University, Japan. Resected tissues were immediately frozen and stored in liquid nitrogen. Histopathological diagnosis of each neoplastic tissue was performed, according to the World Health Organization criteria, by the Department of Pathology, Chiba University Hospital. Clinicopathological staging was determined by the TNM classification of the International Union against Cancer. Total RNA was isolated by means of an SV Total RNA isolation system (Promega, Madison, WI, USA) according to the manufacturer's protocol. The samples were stored at $-80^{\circ} \mathrm{C}$ until use.

Preparation of labeled probes and hybridization on oligonucleotide arrays. The AceGene Human oligo chip (30K) (Hitachi Software Engineering Co., Ltd., Kanagawa, Japan) containing 10,800 probes was used for mRNA expression profiling. We obtained information for each gene on the chips from the National Center for Biotechnology information database, and the experiments for the oligonucleotide microarray were performed according to the manufacturer's instructions (http://dnasis.hskbio.hitachisk.co.jp/acegene/). Briefly, cDNA probes labeled with aminoallyl-dUTP (Ambion Inc., Austin, TX, USA) were synthesized using Oligo(dT) primer and SuperScript II (Invitrogen, Carlsbad, CA, USA), and were purified using the QIAquick PCR purification kit (Qiagen K K., Tokyo, Japan).

The labeled test and reference cDNA probes were coupled with Cy3- and Cy5-monoreactive dye (Amersham Biosciences Inc., Tokyo, Japan), respectively, and purified using microbio-spin columns (Bio-Rad Laboratories Inc., Tokyo, Japan).

Extraction of candidate genes from microarray data. To identify the potential biomarker genes that reflect the state of cervical lymph node metastasis, all gene expression data sets were statistically compared between the patients with nodepositive and node-negative disease. Because our ultimate objective was to divide OSCC cases into groups on the basis of node positivity and negativity, a permutation test was most suitable for indicating overlapping patterns between the gene expression data from the two groups. We used an absolute value of a difference of the mean to evaluate the level of separate distribution patterns between the groups. The gene expression data set was further estimated by Significance Analysis of Microarrays (SAM), a software program specifically designed to identify differentially expressed genes from microarray data (19). To control for the false discovery rate among genes that are considered changed, SAM assigns a score to each gene on the basis of the change in gene expression relative to the discrimination score of repeated measurements. Then, to identify possible functional groups of cooperating or coregulated genes in OSCC tissue, hierarchical clustering was applied to the expression data, using the average-linkage clustering algorithms in Cluster.

\section{Results}

Identification of candidate OSCC with cervical lymph node metastasis target genes. The characteristics of the patients and tumors are shown in Table I. The clustering of all the microarray data was used to classify the 15 OSCCs into two meaningful groups based on pathological node positivity $(\mathrm{n}=5)$ and node negativity $(\mathrm{n}=10)$. We identified a 20 -gene signature for node positivity (Fig. 1) by regression analysis. The distribution of the total expression of 20 candidate genes was identified between the node-positive and node-negative groups within the training data set (Fig. 1).

Prediction of lymph node status in the training set. Analysis of the training data set using microarray analysis identified 20 genes that were correlated with the pathological lymph node status (Table II). The 20-gene classification algorithm generated on the training set was applied to the data as a testing set. The expression patterns of the 20 genes in the eight independent OSCC sets were similar to those in the 15 cases of the training set.

Functional annotation of 20 genes identified from OSCCderived training set. Functional annotation analysis of the 20 genes was performed, and they were grouped and named according to the Gene Ontology convention (20). Information on the four functional categories, i.e., biological process, cellular component, molecular function, and cancer-related gene, was collected from the 20 genes and shown in Table II.

Prediction of lymph node status in the testing set. The 20gene classification algorithm generated by the training set was then applied to the data from the eight independent OSCCs as a validation test. In this data set, the classification accuracy for the training set in node-positive cases remained high $(100 \% ; 3 / 3)$ but accuracy in the node-negative group was $80 \%(4 / 5)$. Overall, classification accuracy for microarray in the testing set was $87 \%(7 / 8)$ when compared with pathology. The classification probabilities for individual samples were similar to those in the testing set with $100 \%$ probability for 0 samples, $80 \%$ to $99 \%$ for three samples, and $45 \%$ to $80 \%$ for five samples (Fig. 2).

\section{Discusion}

Clustering analysis of tumor samples on the basis of gene expression might facilitate a detailed diagnosis of individual cancers. Recently, a cDNA microarray system was used to 
Table I. Clinicopathological characteristics of patients and their tumors.

\begin{tabular}{|c|c|c|c|c|c|c|c|c|c|}
\hline \multirow[b]{2}{*}{ Clinical classification } & \multicolumn{4}{|c|}{ Training set } & No. of patients $(\%)$ & \multicolumn{3}{|c|}{ Testing set } & No. of patients (\%) \\
\hline & Total & & $\mathrm{pN}^{+}$ & $\mathrm{pN}^{-}$ & P-value & Total & $\mathrm{pN}^{+}$ & $\mathrm{pN}^{-}$ & P-value \\
\hline Age at surgery & & & & & 0.5338 & & & & 1 \\
\hline$<60$ & 8 & 4 & $(50)$ & $4 \quad(50)$ & & 3 & 1 (33) & $2(67)$ & \\
\hline$\geq 60,<70$ & 1 & 0 & & $1(100)$ & & 2 & $1 \quad(50)$ & $1 \quad(50)$ & \\
\hline$\geq 70$ & 6 & 1 & (17) & $5 \quad(83)$ & & 3 & $1 \quad(33)$ & $2 \quad(67)$ & \\
\hline Gender & & & & & 0.714393 & & & & 0.465209 \\
\hline Male & 8 & 3 & (37) & $5 \quad(63)$ & & 4 & $2(50)$ & $2(50)$ & \\
\hline Female & 7 & 2 & $(28)$ & $5 \quad(72)$ & & 4 & $1 \quad(25)$ & $3 \quad(75)$ & \\
\hline $\mathrm{T}$-primary tumor & & & & & 1 & & & & 1 \\
\hline $\mathrm{T} 1$ & 0 & 0 & & 0 & & 0 & 0 & 0 & \\
\hline $\mathrm{T} 2$ & 1 & 0 & & $1(100)$ & & 0 & 0 & 0 & \\
\hline $\mathrm{T} 3$ & 6 & 2 & (33) & $4 \quad(67)$ & & 4 & $1 \quad(25)$ & $3(75)$ & \\
\hline $\mathrm{T} 4$ & 8 & 3 & $(37)$ & $5 \quad(63)$ & & 4 & $2(50)$ & $2(50)$ & \\
\hline N-regional lymph node & & & & & 0.000333 & & & & 0.00467773 \\
\hline $\mathrm{N}^{-}$ & 10 & 0 & & $10(100)$ & & 5 & 0 & $5(100)$ & \\
\hline $\mathrm{N}^{+}$ & 5 & & $(100)$ & 0 & & 3 & $3(100)$ & 0 & \\
\hline Stage & & & & & 0.230769 & & & & 1 \\
\hline $\mathrm{I}$ & 0 & 0 & & 0 & & 0 & 0 & 0 & \\
\hline II & 1 & 0 & & $1(100)$ & & 0 & 0 & 0 & \\
\hline III & 4 & 0 & & $4(100)$ & & 4 & $1 \quad(25)$ & $3 \quad(75)$ & \\
\hline IV & 10 & 5 & $(50)$ & $5 \quad(50)$ & & 4 & $2(50)$ & $2(50)$ & \\
\hline Histopathological type & & & & & 0.56044 & & & & 1 \\
\hline Well differentiated & 11 & 3 & $(27)$ & $8 \quad(73)$ & & 7 & $3(43)$ & $4 \quad(57)$ & \\
\hline Moderately differentiated & 4 & 2 & $(50)$ & $2 \quad(50)$ & & 1 & 0 & $1(100)$ & \\
\hline Poorly differentiated & 0 & 0 & & 0 & & 0 & 0 & 0 & \\
\hline Tumor site & & & & & 0.246753 & & & & 0.678571 \\
\hline Gingiva & 1 & & $(100)$ & 0 & & 0 & 0 & 0 & \\
\hline Tongue & 10 & 2 & $(20)$ & $8 \quad(80)$ & & 4 & $1 \quad(25)$ & $3(75)$ & \\
\hline Buccal mucosa & 0 & 0 & & 0 & & 1 & 0 & $1(100)$ & \\
\hline Oral floor & 2 & 1 & $(50)$ & $1 \quad(50)$ & & 3 & $2(67)$ & $1 \quad(33)$ & \\
\hline Orpharyngeal isthmus & 2 & 1 & $(50)$ & $1 \quad(50)$ & & 0 & 0 & 0 & \\
\hline Lower lip & 0 & 0 & & 0 & & 0 & 0 & 0 & \\
\hline Soft palate & 0 & 0 & & 0 & & 0 & 0 & 0 & \\
\hline
\end{tabular}

identify the genes involved in many types of malignant tumors, such as malignant lymphoma (21), hepatocellular carcinoma (22), breast cancer (23), prostate cancer (24), colorectal cancer (25), lung carcinoma (26), esophageal cancer (27), gastric cancer (28), and ovarian carcinoma (29). Although investigators have reported possible regulators related to the lymph node metastasis of cancer cells, the available information is still very limited. We can now recognize a novel type of classification based on gene expression by exploring a large number of cancerous tissues, and current methods of cancer therapy might be improved if this novel classification could be implemented.

The cluster analysis undertaken in this study identified candidate genes associated with lymph node metastasis in 15 OSCCs. These results demonstrate that measurable differences in gene expression exist between node-positive and node-negative primary tumors and that these differences are sufficient to predict the nodal status of an independent set of patients using a leave-one-out cross-validation approach $(9,10)$. Despite the relatively small sample size, significance 
training set

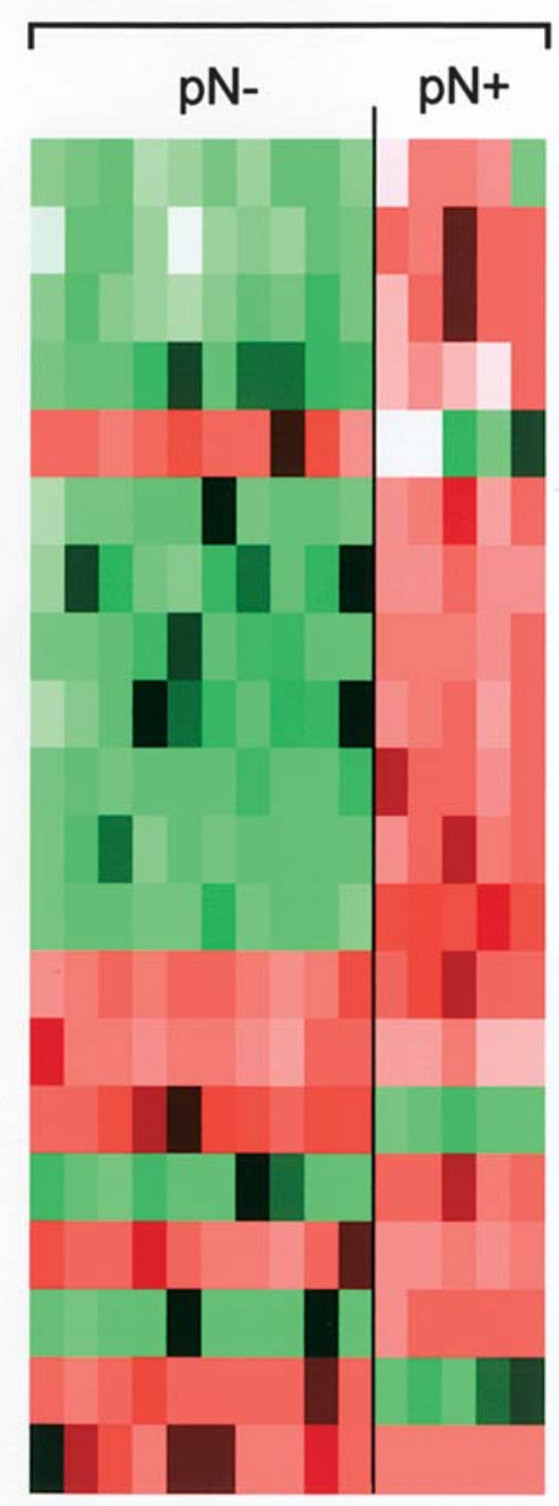

test set

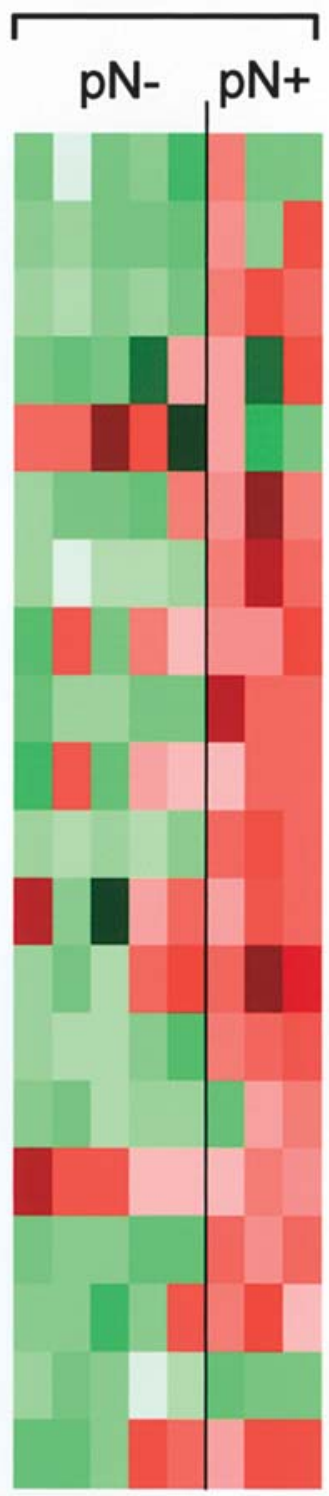

$\log _{2}$

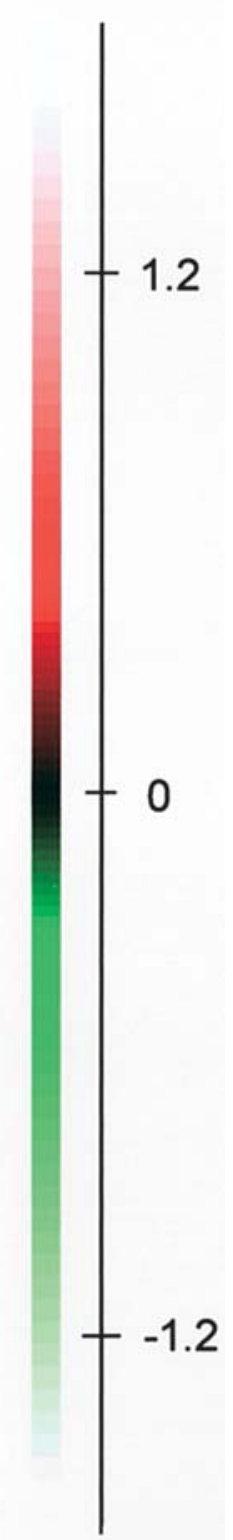

Figure 1. Selection procedures for lymph node metastasis. pN- indicates node negativity and $\mathrm{pN}+$ node positivity.

was high. In the current study, we sought to determine whether the analysis of gene expression patterns in primary OSCCs could predict lymph node status and, if so, predict outcome in individual patients, many of whom are presumed to have lymph node metastases. For this, we used pathological lymph node status as the training classifier and SAM to identify gene expression patterns that specifically correlate with pathological nodal status. Twenty significant genes were associated with metastasis to the lymph nodes.

One limitation of the current study is that the patients with node-negative disease may actually have occult nodal involvement and, therefore, our gold standard for the training classifier is not necessarily accurate in pathologically nodenegative cases. However, it should be $100 \%$ accurate in the case of node-positive tumors. Indeed, in both the training and testing data sets, we found extremely high (88\%) concor- dance between microarray analysis and pathological node status for tumors with pathologically positive lymph nodes. In node-negative tumors, however, microarray analysis of the training set data predicted that one of five $(20 \%)$ nodenegative tumors was actually node-positive. We believe that the poor outcome in the patients who tested as node-negative reflects understaging (possibly occult nodal disease) in a higher than normal percentage of patients, and to some degree this is responsible for the high number of patients considered node-positive in microarray analysis. We hypothesize that this inability to attain a good classification accuracy (even within the training set itself) may be the result of a high frequency of occult lymph node disease in this patient set. This may be a result of differences between the two microarray data sets or may reflect the need to refine the analysis tools used for prediction. Another possibility is that 
Table II. Twenty candidate genes for cervical lymph node metastasis.

\begin{tabular}{|c|c|c|c|}
\hline Gene name & Accession no. & Symbol & Description \\
\hline similar to $40 \mathrm{~s}$ s $3 \mathrm{~A}$ & XM_517871 & RPS3A & similar to 40 s ribosomal protein s3a; loc 137437 \\
\hline ribosomal protein L32 & NM_000994_1 & RPL32 & ribosomal protein $132 ;$ rpl32 \\
\hline ribosomal protein $\mathrm{S} 28$ & NM_001031_1 & RPS28 & ribosomal protein $\mathrm{s} 28 ; \operatorname{rps} 28$ \\
\hline $\begin{array}{l}\text { ornithine aminotransferase } \\
\text { (gyrate atrophy) }\end{array}$ & NM_000274_1 & OAT & ornithine aminotransferase precursor; oat \\
\hline alpha-2-hs-glycoprotein; ahsg & NM_001622_1 & AHSG & alpha-2-hs-glycoprotein; ahsg \\
\hline ribosomal protein $\mathrm{S} 8$ & NM_001012_1 & RPS8 & ribosomal protein s8; rps8 \\
\hline ribosomal protein S11 & NM_001015_1 & RPS11 & ribosomal protein s11; rps11 \\
\hline $\begin{array}{l}\text { aldehyde dehydrogenase } 3 \text { family, } \\
\text { member A2 }\end{array}$ & NM_000382_1 & ALDH3A2 & aldehyde dehydrogenase $3 \mathrm{a} 2$; aldh $3 \mathrm{a} 2$ \\
\hline $\begin{array}{l}\text { cadherin } 1 \text {, type } 1, \text { E-cadherin } \\
\text { (epithelial) }\end{array}$ & NM_004360_1 & CDH1 & cadherin 1 , type 1 preproprotein; cdh 1 \\
\hline src homology three (SH3) & NM_003149_1 & STAC & src homology three (sh3) and cysteine \\
\hline and cysteine rich domain & & & rich domain; stac \\
\hline ribosomal protein $\mathrm{S} 24$ & NM_001026_1 & RPS24 & ribosomal protein s24, isoform c; rps24 \\
\hline flj22184 & NM_025094_1 & FLJ22184 & hypothetical protein flj22184; flj22184 \\
\hline tenascin C (hexabrachion) & NM_002160_1 & TNC & hexabrachion (tenascin c, cytotactin); hxb \\
\hline pro1316 - n - n & NM_018580_1 & PRO1316 & hypothetical protein pro1316; pro1316 \\
\hline absent in melanoma 1-like & NM_017977_1 & AIM1L & absent in melanoma 1-like \\
\hline Ras-related GTP binding A & NM_006570_1 & RRAGA & ras-related gtp-binding protein; raga \\
\hline $\begin{array}{l}\text { prostate androgen-regulated } \\
\text { transcript } 1\end{array}$ & NM_016590 & PART1 & $\begin{array}{l}\text { prostate androgen-regulated transcript } 1 \text { protein; } \\
\text { part1 }\end{array}$ \\
\hline ribosomal protein L3 & NM_000967_1 & RPL3 & ribosomal protein 13 ; rpl3 \\
\hline $\begin{array}{l}\text { small EDRK-rich factor } 1 \mathrm{~A} \\
\text { (telomeric) }\end{array}$ & NM_021967_1 & SERF1A & small edrk-rich factor 1a, telomeric; serf1a \\
\hline immediate early response 2 & NM_004907_1 & IER2 & immediate early protein; etr101 \\
\hline
\end{tabular}

\section{Test Probabilities}

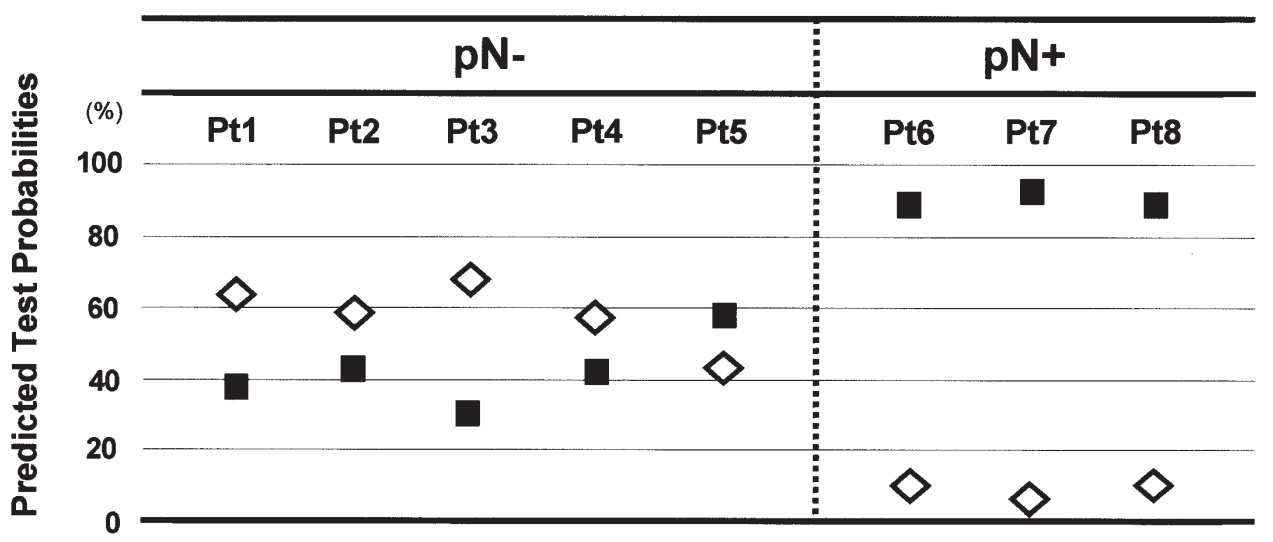

Figure 2. Classification probability for the test set. Original sample names and pathological lymph node status are labeled on the top of each graph. Classified nodal status is indicated by $\diamond$, indicating node negativity and $\mathbf{m}$, indicating node positivity, with the $\mathrm{Y}$ axis indicating the probability associated with the classification of each patient.

some of the misclassified tumors actually have the potential to metastasize $(2,5,30)$ but have not yet done so.

In conclusion, our analysis of gene expression in primary tumors correlated very highly in pathologically node-positive patients. This analysis may identify patients whose tumors have already metastasized or have the potential to do so. However, a problem with this data interpretation is that we do not have actual data on occult lymph node disease in 
patients who are node-negative. This problem may be resolved in a situation in which tumor gene expression, accurate clinical and surgical staging, and the presence of occult nodal disease are determined in the same set of patients.

\section{Acknowledgements}

The authors thank Lynda C. Charters for editing this manuscript.

\section{References}

1. Greenberg JS, Fowler R, Gomez J, Mo V, Roberts D, El Naggar AK and Myers JN: Extent of extracapsular spread: a critical prognosticator in oral tongue cancer. Cancer 97: 1464-1470, 2003.

2. Ramaswamy S, Ross KN, Lander ES and Golub TR: A molecular signature of metastasis in primary solid tumors. Nat Genet 33: 49-54, 2003.

3. Bertucci F, Salas S, Eysteries S, Nasser V, Finetti P, Ginestier C, Charafe-Jauffret E, Loriod B, Bachelart L, Montfort J, Victorero G, Viret F, Ollendorff V, Fert V, Giovaninni M, Delpero JR, Nguyen C, Viens P, Monges G, Birnbaum D and Houlgatte R: Gene expression profiling of colon cancer by DNA microarrays and correlation with histoclinical parameters. Oncogene 23: 1377-1391, 2004

4. He Y, Kozaki K-I, Karpanen T, Koshikawa K, Yla-Herttuala S, Takahashi T and Alitarou K: Suppression of tumor lymphangiogenesis and lymph node metastasis by blocking vascular endothelial growth factor receptor 3 signaling. J Natl Cancer Inst 94: 819-825, 2002.

5. Kikuchi T, Daigo Y, Katagiri T, Tsunoda T, Okada K, Kakiuchi S, Zembutsu H, Furukawa Y, Kawamura M, Kobayashi K, Imai K and Nakamura Y: Expression profiles of non-small cell lung cancers on cDNA microarrays: identification of genes for prediction of lymph-node metastasis and sensitivity to anticancer drugs. Oncogene 22: 2192-2205, 2003.

6. Nakamura T, Furukawa Y, Nakagawa H, Tsunoda T, Ohigashi H, Murata K, Ishikawa O, Ohgaki K, Kashimura N, Miyamoto M, Hirano S, Kondo S, Katoh H, Nakamura Y and Katagiri T: Genome-wide cDNA microarray analysis of gene expression profiles in pancreatic cancers using populations of tumor cells and normal ductal epithelial cells selected for purity by laser microdissection. Oncogene 23: 2385-2400, 2004.

7. Alevizos I, Mahadevappa M, Zhang X, Ohyama H, Kohno Y and Posner M: Oral cancer in vivo gene expression profiling assisted by laser capture microdissection and microarray analysis. Oncogene 20: 6196-6204, 2001

8. Belbin TJ, Singh B, Barber I, Socci N, Wenig B, Smith R, Prystowsky MB and Childs G: Molecular classification of head and neck squamous cell carcinoma using cDNA microarrays. Cancer Res 62: 1184-1190, 2002.

9. Mendez E, Cheng C, Farwell DG, Ricks S, Agoff SN, Futran ND, Weymuller EA Jr, Maronian NC, Zhao LP and Chen C: Transcriptional expression profiles of oral squamous cell carcinomas. Cancer 95: 1482-1494, 2002.

10. Hwang D, Alevizos I, Schmitt WA, Misra J, Ohyama H, Todd R, Mahadevappa M, Warrington JA, Stephanopoulos G, Wong DT and Stephanopoulos G: Genomic dissection for characterization of cancerous oral epithelium tissues using transcription profiling. Eur J Cancer B Oral Oncol 39: 259-268, 2003.

11. Schmalbach CE, Chepeha DB, Giordano TJ, Rubin MA, Teknos TN, Bradford CR, Wolf GT, Kuick R, Misek DE, Trask DK and Hanash S: Molecular profiling and the identification of genes associated with metastatic oral cavity/pharynx squamous cell carcinoma. Arch Otolaryngol Head Neck Surg 130: 295-302, 2004.

12. Warner GC, Reis PP, Jurisica I, Sultan M, Arora S, Macmillan C, Makitie AA, Grenman R, Reid N, Sukhai M, Freeman J, Gullane P, Irish J and Kamel-Reid S: Molecular classification of oral cancer by cDNA microarrays identifies overexpressed genes correlated with nodal metastasis. Int J Cancer 110: 857-868, 2004.

13. Parkin DM: Global cancer statistics in the year 2000. Lancet Oncol 2: 533-543, 2001.
14. Kim G, Yamabe H and Imada-Shirakata Y : p53 mutation and protein overexpression in the early stages of esophageal tumorigenesis utilizing endoscopically obtained biopsy specimens. Int J Oncol 10: 683-688, 1997.

15. Makino H, Tajiri T, Miyashita M, Sasajima K, Anbazhagan R, Johnston J and Gabrielson E: Differential expression of TCEAL1 in esophageal cancers by custom cDNA microarray analysis. Dis Esophagus 18: 37-40, 2005.

16. Lu J, Liu Z, Xiong M, Wang Q, Wang X, Yang G, Zhao L, Qiu Z, Zhou $\mathrm{C}$ and $\mathrm{Wu} \mathrm{M}$ : Gene expression profile changes in initiation and progression of squamous cell carcinoma of esophagus. Int J Cancer 91: 288-294, 2001

17. Anbazhagan R, Tihan T, Bornman DM, Johnston JC, Saltz JH, Weigering A, Piantadosi S and Gabrielson E: Classification of small cell lung cancer and pulmonary carcinoid by gene expression profiles. Cancer Res 59: 5119-5122, 1999.

18. Hedenfalk I, Duggan D, Chen Y, Radmacher M, Bittner M, Simon R, Meltzer P, Gusterson B, Esteller M, Kallioniemi OP, Wilfond B, Borg A and Trent J: Gene-expression profiles in hereditary breast cancer. N Eng J Med 344: 539-548, 2001.

19. Tusher VG, Tibshirani R and Chu G: Significance analysis of microarrays applied to the ionizing radiation response. Proc Natl Acad Sci USA 98: 5116-5121, 2001.

20. Ashburner M, Ball CA, Blake JA, Botstein D, Butler H, Cherry JM, Davis AP, Dolinski K, Dwight SS, Eppig JT, Harris MA, Hill DP, Issel-Tarver L, Kasarskis A, Lewis S, Matese JC, Richardson JE, Ringwald M, Rubin GM and Sherlock G: Gene ontology: tool for the unification of biology. The Gene ontology Consortium. Net Genet 25: 25-29, 2000.

21. Pan KH, Lih CJ and Cohen SN: Effects of threshold choice on biological conclusions reached during analysis of gene expression by DNA microarrays. Proc Natl Acad Sci USA 102: 8961-8965, 2005.

22. Ng RK, Lau CY, Lee SM, Tsui SK, Fung KP and Waye MM: cDNA microarray analysis of early gene expression profiles associated with hepatitis B virus $X$ protein-mediated hepatocarcinogenesis. Biochem Biophys Res Commun 322: 827-835, 2004.

23. Wang Y, Klijn JG, Zhang Y, Sieuwerts AM, Look MP, Yang F, Talantov D, Timmermans M, Meijer-van Gelder ME, Yu J, Jatkoe T, Berns EM, Atkins D and Foekens JA: Gene expression profiles to predict distant metastasis of lymph-nodenegative primary breast cancer. Lancet 365: 671-679, 2005.

24. Assikis VJ, Do KA, Wen S, Wang X, Cho-Vega JH, Brisbay S, Lopez R, Logothetis CJ, Troncoso P, Papandreou CN and McDonnell TJ: Clinical and biomarker correlates of androgenindependent, locally aggressive prostate cancer with limited metastatic potential. Clin Cancer Res 10: 6770-6778, 2004.

25. Croner RS, Peters A, Brueckl WM, Matzel KE, Klein-Hitpass L, Brabletz T, Papadopoulos T, Hohenberger W, Reingruber B and Lausen B: Microarray versus conventional prediction of lymph node metastasis in colorectal carcinoma. Cancer 104: 395-404, 2005.

26. Xi L, Lyons-Weiler J, Coello MC, Huang X, Gooding WE, Luketich JD and Godfrey TE: Prediction of lymph node metastasis by analysis of gene expression profiles in primary lung adenocarcinomas. Clin Cancer Res 11: 4128-4135, 2005.

27. Tamoto E, Tada M, Murakawa K, Takada M, Shindo G, Teramoto K, Matsunaga A, Komuro K, Kanai M, Kawakami A, Fujiwara Y, Kobayashi N, Shirata K, Nishimura N, Okushiba S, Kondo S, Hamada J, Yoshiki T, Moriuchi T and Katoh H: Gene expression profile changes correlated with tumor progression and lymph node metastasis in esophageal cancer. Clin Cancer Res 10: 3629-3638, 2004

28. Chen J, Rocken C, Klein-Hitpass L, Gotze T, Leodolter A, Malfertheiner P and Ebert MP: Microarray analysis of gene expression in metastatic gastric cancer cells after incubation with the methylation inhibitor 5-aza-2'-deoxycytidine. Clin Exp Metastasis 21: 389-397, 2004.

29. Wang E, Ngalame Y, Panelli MC, Nguyen-Jackson H, Deavers M, Mueller P, Hu W, Savary CA, Kobayashi R, Freedman RS and Marincola FM: Peritoneal and subperitoneal stroma may facilitate regional spread of ovarian cancer. Clin Cancer Res 11: 113-122, 2005.

30. Huang E, Cheng SH, Dressman H, Pittman J, Tsou MH, Horng CF, Bild A, Iversen ES, Liao M, Chen CM, West M, Nevins JR and Huang AT: Gene expression predictors of breast cancer outcomes. Lancet 361: 1590-1596, 2003. 